\title{
Method of utilization of the spent vanadium catalyst
}

\author{
Krzysztof Mazurek $^{1^{*}}$, Piotr Grzesiak ${ }^{2}$, Sebastian Drużyński ${ }^{1}$, Urszula Kiełkowska ${ }^{1}$, Adriana \\ Wróbel $^{1}$, Aleksandra Szalla ${ }^{1}$ \\ ${ }^{1}$ Nicolaus Copernicus University in Toruń, Faculty of Chemistry, ul. Gagarina 7, 87-100 Toruń, Poland \\ ${ }^{2}$ Institute of Plant Protection - National Research Institute, ul. Władystawa Wegorka 20, 60-318 Poznań \\ *Corresponding author: e-mail: k.mazurek@umk.pl
}

\begin{abstract}
A spent vanadium catalyst, from the plant of metallurgical type, was leached in a potassium hydroxide solution to recover vanadium. The effect of time, temperature, concentration of basic, catalyst particle size and phase ratio was studied. The results showed that for a 160-750 $\mu \mathrm{m}$ catalyst leached for $4 \mathrm{~h}$ at $313.15 \mathrm{~K}$ in the presence of $10 \%$ potassium hydroxide solution at a liquid: solid ratio of $20: 1$, the extent of leaching of $\mathrm{V}$ was about $87 \%$. Additionally, separation of vanadium from such a solution was investigated by the ion exchange method. Two types of polymer strongly basic ion exchangers were used. The ion exchange tests indicate that vanadium were loaded from the post-leaching solution with high efficiency. On this basis a flowsheet for the proposed process of a complex utilization of the spent vanadium catalyst is presented.
\end{abstract}

Keywords: potassium hydroxide, spent vanadium catalysts, leaching, recovery, ion exchange, vanadium, copper, zinc, arsenic, lead, Amberlite ${ }^{\circledR}$ IRA958, Dowex ${ }^{\circledR}$ 1X2.

\section{INTRODUCTION}

The vanadium catalyst used in the oxidation of $\mathrm{SO}_{2}$ to $\mathrm{SO}_{3}$ loses its catalytic properties, due to a number of changes which take place in its texture and structure, and becomes dangerous industrial waste. This waste constitutes one of the basic problems of the sulphuric(VI) acid industry, which require a comprehensive solution ${ }^{1-7}$.

Independently of the type of installation, the basic components of spent vanadium catalysts are vanadium, potassium compounds, sulfates and iron. Catalysts removed from plants, which process gas utilized for roasting copper ore also contain amounts of copper, zinc, arsenic and lead ${ }^{3}$.

Stored catalyst can be an environmental hazard. The danger comes primarily from risk of harmful compounds within the catalysts leaching into soil and water. The presence of free $\mathrm{SO}_{3}$, sulphates and humidity all mean that the leachate has an acidic $\mathrm{pH}$, which can systematically increase over time, leading to increased mobility of the contaminants within the waste ${ }^{1-7}$.

The following paper presents data determining the optimal leaching parameters of the spent vanadium catalyst from a metallurgic installation using potassium hydroxide solutions and the results of an investigation into the possibility of recovering vanadium ions from the leached solution through ion exchange. The findings of this investigation serve as basis for a proposed method of utilizing a spent vanadium catalyst.

\section{EXPERIMENTAL SECTION}

\section{Reagents and Apparatus}

The spent vanadium catalyst was sampled from the waste deposit of Copper Smelter in Głogów, Poland, the factory producing the sulfuric acid in the contact process; KOH (cz.d.a.) - Avantor, Polska; Amberlite ${ }^{\circledR}$ IRA958, Fluka Analytical; Dowex ${ }^{\circledR}$ 1X2, Sigma - Aldrich, Vanadium standard for AAS, $1000 \mathrm{mg} / \mathrm{l}$, Fluka Analytical; Iron standard for AAS, $1000 \mathrm{mg} / \mathrm{l}$, Fluka Analytical; Copper standard for AAS, $1000 \mathrm{mg} / \mathrm{l}$, Fluka Analytical; Zinc standard for AAS, $1000 \mathrm{mg} / \mathrm{l}$, Fluka Analytical;
Lead standard for AAS, $1000 \mathrm{mg} / \mathrm{l}$, Fluka Analytical; Arsenic standard for AAS, $1000 \mathrm{mg} / \mathrm{l}$, Fluka Analytical.

Before research, the catalyst was milled in the vibrational mill, and divided into the appropriate granulometric fractions with the FRITSH set of sieves. Table 1 presents the composition of the spent vanadium catalyst used to the researches.

Table 1. The content of the studied compounds in the spent vanadium catalyst

\begin{tabular}{|c|c|c|c|c|c|c|}
\hline \multirow{3}{*}{$\begin{array}{c}\text { Content } \\
\%\end{array}$} & \multicolumn{6}{|c|}{ Compound } \\
\cline { 2 - 7 } & $\mathrm{V}_{2} \mathrm{O}_{5}$ & $\mathrm{Fe}_{2} \mathrm{O}_{3}$ & $\mathrm{CuO}$ & $\mathrm{ZnO}$ & $\mathrm{As}_{2} \mathrm{O}_{3}$ & $\mathrm{PbO}$ \\
\cline { 2 - 7 } & 5.44 & 0.91 & 0.02 & 0.01 & 0.01 & 0.01 \\
\hline
\end{tabular}

PANalytical's MiniPal 4 compact energy dispersive $\mathrm{X}$-ray spectrometer was employed to determine the concentrations of studies ions in solution.

Laboratory shaker Elpan 357 with the water bath was employed for mixing test solutions at a constant temperature. The temperature in the bath was controlled by an electronic thermometer with preccision of $0.2 \mathrm{~K}$.

Elmetron's multifunctional CX-742 device equipped with Ionode's Ion44C combination electrode was employed to test of the $\mathrm{pH}$ of the solutions.

Thermo Scientific's Pascal 240 mercury porosimeter was employed to determine the porous structure of the recovered silica.

\section{EXPERIMENTAL METHODS}

\section{Leaching process}

The effect of time and temperature of leaching, basic concentration, particle size, as well as mass solid to liquid ratio $\left(\mathrm{S}: \mathrm{L}\left(\mathrm{g}: \mathrm{cm}^{3}\right)\right)$ on the efficiency of the recovery of vanadium compounds from the spent catalyst was investigated. Weighed samples of the vanadium catalyst underwent agitation leaching in a range of different solutions at constant temperature $(+/-0.5 \mathrm{~K})$. After the required time, the solution was separated by vacuum filtration. 
The clear solution was transferred into the flask, diluted with the distilled water and analyzed to determine the concentration of vanadium, iron, copper, zinc, arsenic and lead compounds.

\section{Separation process}

The investigation was conducted using the static method. The $\mathrm{pH}$, time, temperature, and the volume of the solution were investigated for effects on the degree of adsorption of vanadium ions from a solution leached from a spent vanadium catalyst.

In the investigation $1.000 \mathrm{~g}$ of anionite was weighed and transferred into an Erlenmeyer flask. A appropriate volume of the solution leached from a spent vanadium catalyst was transferred into the flask using a volumetric pipette. The flask was then airtightly stopped with a rubber stopper and placed into a thermoregulator. The samples were vigorously shaken at a constant temperature. After a set time the shaking was stopped. Next, the entirety was quantitatively transferred onto a filter and filtered into a $50 \mathrm{~cm}^{3}$ flask to separate the solution from the anionite. The ionite on the filter was washed with small amounts of distilled water multiple times. The solution in the flask was diluted with distilled water and analyzed chemically to establish the concentration of vanadium ions.

\section{Analytical methods}

Concentration of all ions in solutions was determined using the EDXRF method ${ }^{8}$. Quantitative analysis of studied components was carried out based on calibration curves. For the preparation of solutions with known concentration of studied elements were used the standard solutions for AAS with the concentration of $1000 \mathrm{mg} / \mathrm{l}$.

The calibration in EDXRF method determines the relationship between the concentration of elements and the intensity of the fluorescent lines of those elements ${ }^{\mathbf{8}}$.

Than the intensities of the elements with unknown concentration are measured, with the corresponding concentration being determined from the calibration ${ }^{8}$.

\section{RESULTS AND DISCUSSION}

\section{Leaching test}

Analyses of the investigated solutions meant to determine the effect of temperature on the level of leaching of the compounds investigated are shown in Table 2 and Figure 1. The data shows that the temperature of the leaching process affects the obtained results. Leaching of a spent catalyst with a $10 \%$ solution of $\mathrm{KOH}$ over $1 \mathrm{~h}$ at $293.15 \mathrm{~K}$ allows for the leaching of around $75 \%$ of vanadium compounds. The highest efficiency of $86 \%$ for vanadium leaching was achieved at 333.15 $\mathrm{K}$. In the case of compounds constituting the catalyst's contaminants, temperature significantly affects only the leaching of iron compounds. Along with the increase of the process' temperature the level of iron compounds leached decreases systematically. At $293.15 \mathrm{~K}$ the concentration of iron compounds in the leachate solution was $0.027 \mathrm{~g} \cdot \mathrm{dm}^{-3}$, and at $333.15 \mathrm{~K}$ the concentration decreased to $0.013 \mathrm{~g} \cdot \mathrm{dm}^{-3}$.

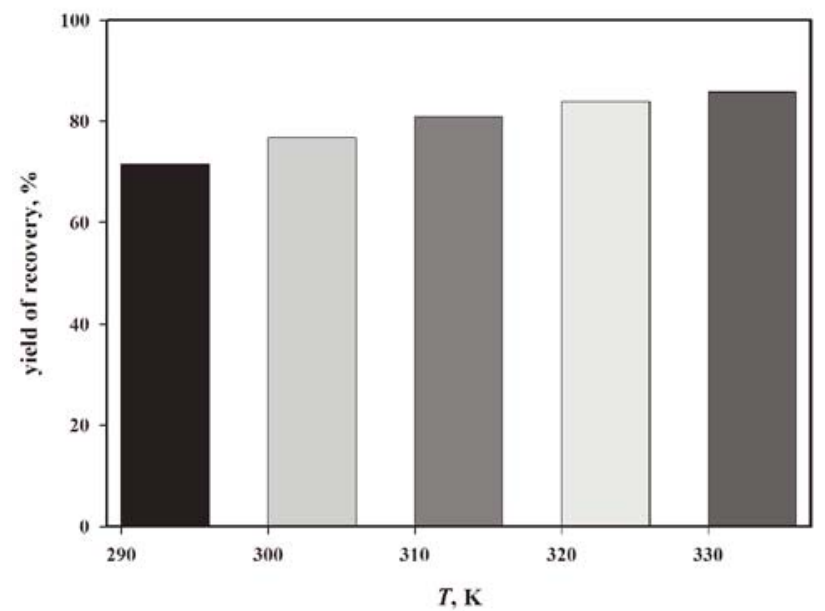

Figure 1. Effect of temperature of leaching process on the efficiency of recovery of vanadium compounds $\left(\mathrm{c}_{\mathrm{KOH}}=\right.$ $\left.10 \%, \tau=1 \mathrm{~h}, \mathrm{~S}: \mathrm{L}=1: 10\left(\mathrm{~g}: \mathrm{cm}^{3}\right), \varphi=160-750 \mu \mathrm{m}\right)$

Table 3 and Figure 2 show the result of an experiment meant to find the effect of time on the degree of leaching of a spent catalyst using a $10 \%$ solution of $\mathrm{KOH}$. The data shows that the duration of the process significantly

Table 2. Effect of the leaching temperature on the concentration of the studied compounds in post - leaching solution $\left(\mathrm{c}_{\mathrm{KOH}}=10 \%, \tau=1 \mathrm{~h}, \mathrm{~S}: \mathrm{L}=1: 10\left(\mathrm{~g}: \mathrm{cm}^{3}\right), \varphi=160-750 \mu \mathrm{m}\right)$

\begin{tabular}{|c|c|c|c|c|c|}
\hline \multirow{2}{*}{$T, \mathrm{~K}$} & \multicolumn{5}{|c|}{$c, \mathrm{~g} \cdot \mathrm{dm}^{-3}$} \\
\cline { 2 - 5 } & $\mathrm{Fe}_{2} \mathrm{O}_{3}$ & $\mathrm{CuO}$ & $\mathrm{ZnO}$ & $\mathrm{As}_{2} \mathrm{O}_{3}$ \\
\hline 293.15 & 0.027 & 0.003 & 0.002 & 0.007 \\
\hline 303.15 & 0.019 & 0.002 & 0.002 & 0.002 \\
\hline 313.15 & 0.014 & 0.003 & 0.002 & 0.006 \\
\hline 323.15 & 0.014 & 0.003 & 0.002 & 0.006 & 0.006 \\
\hline 333.15 & 0.013 & 0.003 & 0.002 & 0.003 & 0.006 \\
\hline
\end{tabular}

Table 3. Effect of leaching time on the concentration of the studied compounds in post - leaching solution $\left(\mathrm{c}_{\mathrm{KOH}}=10 \%\right.$, $\left.T=293.15 \mathrm{~K}, \mathrm{~S}: \mathrm{L}=1: 10\left(\mathrm{~g}: \mathrm{cm}^{3}\right), \varphi=160-750 \mu \mathrm{m}\right)$

\begin{tabular}{|c|c|c|c|c|c|}
\hline \multirow{2}{*}{$t, h$} & \multicolumn{5}{|c|}{$c, \mathrm{~g} \cdot \mathrm{dm}^{-3}$} \\
\hline & $\mathrm{Fe}_{2} \mathrm{O}_{3}$ & $\mathrm{CuO}$ & $\mathrm{ZnO}$ & $\mathrm{As}_{2} \mathrm{O}_{3}$ & $\mathrm{PbO}$ \\
\hline 0.5 & 0.027 & 0.001 & 0.002 & 0.007 & 0.002 \\
\hline 1.0 & 0.026 & 0.001 & 0.002 & 0.007 & 0.003 \\
\hline 4.0 & 0.023 & 0.001 & 0.002 & 0.007 & 0.005 \\
\hline 6.0 & 0.022 & 0.001 & 0.002 & 0.007 & 0.005 \\
\hline 8.0 & 0.022 & 0.001 & 0.002 & 0.007 & 0.005 \\
\hline
\end{tabular}




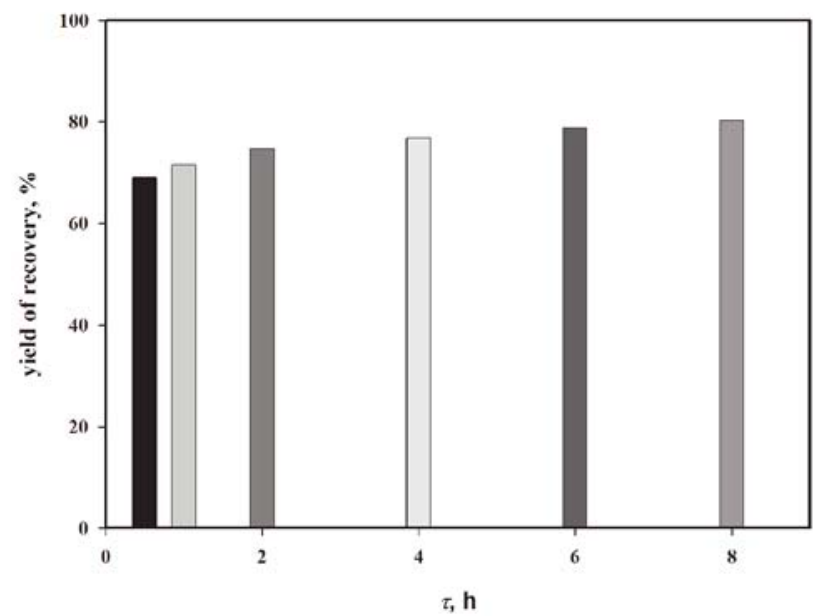

Figure 2. Effect of leaching time on the efficiency of recovery of vanadium compounds $\left(\mathrm{c}_{\mathrm{KOH}}=10 \%, T=293.15 \mathrm{~K}\right.$, $\left.\mathrm{S}: \mathrm{L}=1: 10\left(\mathrm{~g}: \mathrm{cm}^{3}\right), \varphi=160-750 \mu \mathrm{m}\right)$

affects the degree of leaching of vanadium, iron, and lead compounds. In the case of vanadium compounds, increasing the time interval of leaching from 0.5 to 8 $\mathrm{h}$ causes a $11 \%$ increase in efficiency. In the case of iron compounds, increasing the duration of the process from 0.5 to $6 \mathrm{~h}$ causes a decrease in the concentration of iron compounds in the solution leached from a spent vanadium catalyst by about $0.005 \mathrm{~g} \cdot \mathrm{dm}^{-3}$. Further increases in the duration of the process do not affect the concentration of this element in the solution. In the case of lead compounds, increasing the duration of catalyst leaching from 0.5 to $4 \mathrm{~h}$ increases the concentration of the investigated element by $0.003 \mathrm{~g} \cdot \mathrm{dm}^{-3}$.

The results of the chemical analyses of the investigated solutions, meant to determine the effect of the concentration of $\mathrm{KOH}$ in the leaching solution on the levels of vanadium and contaminants leached from a spent vanadium catalyst are shown in Table 4 and Figure 3. Data analysis indicates that the concentration of $\mathrm{KOH}$ in the leaching solution is significant only in the case of iron compounds. Increasing the concentration of potassium hydroxide from 5 to $40 \%$ causes an increase in the concentration of iron compounds in the leachate from 0.011 to $0.048 \mathrm{~g} \cdot \mathrm{dm}^{-3}$.

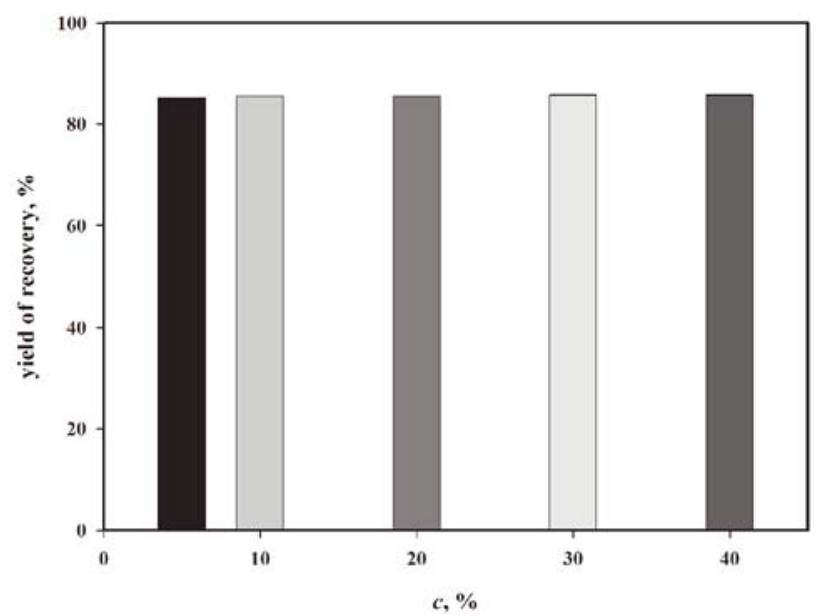

Figure 3. Effect of potassium hydroxide concentration on the efficiency of recovery of vanadium compounds $\left(\tau=4 \mathrm{~h}, \mathrm{~T}=313.15 \mathrm{~K}, \mathrm{~S}: \mathrm{L}=1: 10\left(\mathrm{~g}: \mathrm{cm}^{3}\right), \varphi=\right.$ $160-750 \mu \mathrm{m})$

The results of quantitative analysis of the solutions, meant to determine the effect of the catalyst particle size on the level of individual components recovered from the spent vanadium catalyst using a $\mathrm{KOH}$ solution are presented in Table 5 and Figure 4. The presented data shows that the highest level of vanadium recovery was achieved for a fraction with catalyst particle size between 160 and $750 \mu \mathrm{m}$. The lowest efficiency with respect to vanadium compounds was achieved with the largest catalyst particle size. In the case of iron compounds, the highest concentration of this element was leached from the catalyst with the lowest particle size, and the smallest, by leaching the catalyst with the largest particle size. The effect of catalyst particle size on the concentration of the remainder of the investigated elements is much less significant.

Table 6 and Figure 5 compares the results of the investigation determining the effect of the solid to liquid phase ratio $S: L$ on the level of components leached from a spent vanadium catalyst from a metallurgical installation. Analysis of experimental data unequivocally shows that the volume of the leaching agent has a large effect on the leaching efficiency of vanadium compounds. The lowest efficiency was achieved with an S:L ratio of 1:2.5

Table 4. Effect of potassium hydroxide concentration on the concentration of the studied compounds in post - leaching solution $\left(\tau=4 \mathrm{~h}, \mathrm{~T}=313.15 \mathrm{~K}, \mathrm{~S}: \mathrm{L}=1: 10\left(\mathrm{~g}: \mathrm{cm}^{3}\right), \varphi=160-750 \mu \mathrm{m}\right)$

\begin{tabular}{|c|c|c|c|c|c|}
\hline \multirow{2}{*}{$c, \%$} & \multicolumn{5}{|c|}{$c, \mathrm{~g} \cdot \mathrm{dm}^{-3}$} \\
\cline { 2 - 6 } & $\mathrm{Fe}_{2} \mathrm{O}_{3}$ & $\mathrm{CuO}$ & $\mathrm{ZnO}$ & $\mathrm{As}_{2} \mathrm{O}_{3}$ & $\mathrm{PbO}$ \\
\hline 5 & 0.011 & 0.001 & 0.000 & 0.005 & 0.002 \\
\hline 10 & 0.015 & 0.001 & 0.001 & 0.005 & 0.002 \\
\hline 20 & 0.019 & 0.002 & 0.001 & 0.005 & 0.002 \\
\hline 30 & 0.030 & 0.002 & 0.001 & 0.005 & 0.002 \\
\hline 40 & 0.048 & 0.003 & 0.001 & 0.005 & 0.002 \\
\hline
\end{tabular}

Table 5. Effect of catalyst particle size on the concentration of the studied compounds in post - leaching solution $\left(\mathrm{c}_{\mathrm{KOH}}=10 \%\right.$, $\left.\tau=4 \mathrm{~h}, T=313.15 \mathrm{~K}, \mathrm{~S}: \mathrm{L}=1: 10\left(\mathrm{~g}: \mathrm{cm}^{3}\right)\right)$

\begin{tabular}{|c|c|c|c|c|c|}
\hline \multirow{2}{*}{$\varphi, \mu \mathrm{m}$} & \multicolumn{3}{|c|}{$c, \mathrm{~g} \cdot \mathrm{dm}^{-3}$} \\
\cline { 2 - 5 } & $\mathrm{Fe}_{2} \mathrm{O}_{3}$ & $\mathrm{CuO}$ & \multicolumn{2}{c|}{$\mathrm{As}_{2} \mathrm{O}_{3}$} & $\mathrm{PbO}_{2}$ \\
\hline$>1500$ & 0.012 & 0.001 & 0.000 & 0.004 \\
\hline $750-1500$ & 0.013 & 0.001 & 0.000 & 0.001 \\
\hline $160-750$ & 0.015 & 0.001 & 0.001 & 0.004 \\
\hline $88-160$ & 0.014 & 0.001 & 0.001 & 0.005 \\
\hline$<88$ & 0.014 & 0.002 & 0.002 & 0.005 \\
\hline
\end{tabular}


Table 6. Effect of S:L $\left(\mathrm{g}: \mathrm{cm}^{3}\right)$ ratio on the concentration of the studied compounds in post - leaching solution $\left(\mathrm{c}_{\mathrm{KOH}}=10 \%\right.$, $\tau=4 \mathrm{~h}, T=313.15 \mathrm{~K}, \varphi=160-750 \mu \mathrm{m})$

\begin{tabular}{|c|c|c|c|c|c|}
\hline \multirow{2}{*}{$\mathrm{S}: \mathrm{L}, \mathrm{g}: \mathrm{cm}^{3}$} & \multicolumn{5}{|c|}{$c, \mathrm{~g} \cdot \mathrm{dm}^{-3}$} \\
\hline & $\mathrm{Fe}_{2} \mathrm{O}_{3}$ & $\mathrm{CuO}$ & $\mathrm{ZnO}$ & $\mathrm{As}_{2} \mathrm{O}_{3}$ & $\mathrm{PbO}$ \\
\hline $1: 2.5$ & 0.025 & 0.005 & 0.005 & 0.021 & 0.008 \\
\hline $1: 5$ & 0.015 & 0.002 & 0.002 & 0.009 & 0.002 \\
\hline 1:10 & 0.015 & 0.001 & 0.001 & 0.005 & 0.002 \\
\hline $1: 15$ & 0.015 & 0.000 & 0.001 & 0.004 & 0.002 \\
\hline $1: 20$ & 0.014 & 0.000 & 0.001 & 0.003 & 0.002 \\
\hline
\end{tabular}

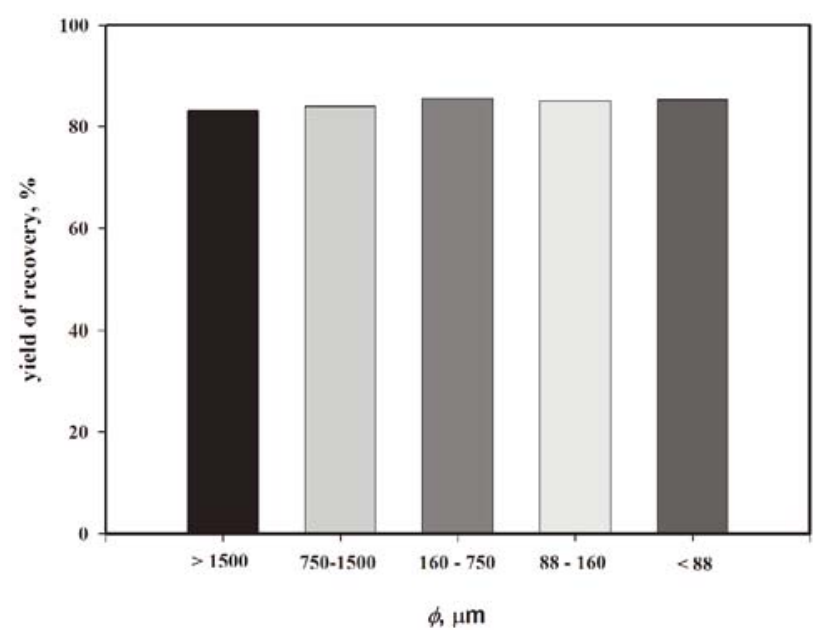

Figure 4. Effect of catalyst particle size on the efficiency of leaching process of the vanadium compounds $\left(\mathrm{c}_{\mathrm{KOH}}=10 \%, \tau=4 \mathrm{~h}, T=313.15, \mathrm{~K}, \mathrm{~S}: \mathrm{L}=1: 10\right.$ $\left.\left(\mathrm{g}: \mathrm{cm}^{3}\right)\right)$

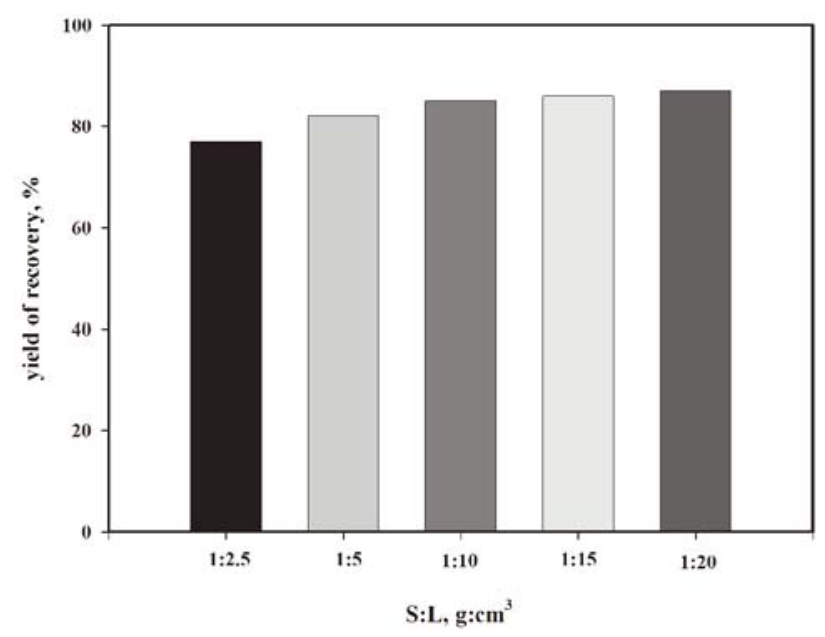

Figure 5. Effect of the ratio of the mass of catalyst to the volume of the leaching factor $\left(\mathrm{S}: \mathrm{L}\left(\mathrm{g}: \mathrm{cm}^{3}\right)\right)$ on the leaching efficacy $\left(\mathrm{c}_{\mathrm{KOH}}=10 \%, \tau=4 \mathrm{~h}, T=\right.$ $313.15 \mathrm{~K}, \varphi=160-750 \mu \mathrm{m})$

and was less than $77 \%$. The highest efficiency, achieved by maintaining a 1:20 solid to liquid phase ratio, was around $87 \%$. Therefore, by increasing the volume of the $\mathrm{KOH}$ solution from 25 to $200 \mathrm{~cm}^{3}$, an around $10 \%$ efficiency increase has been achieved.

\section{Evaluating the quality of the reclaimed silica}

The investigation conducted determined a significant effect of the leaching parameters of the vanadium catalyst in an alkaline environment on the characteristics of the recovered silica (Figure 6 and 7). The silica recovered from leaching the spent vanadium catalyst in an alkaline environment is characterized by slightly

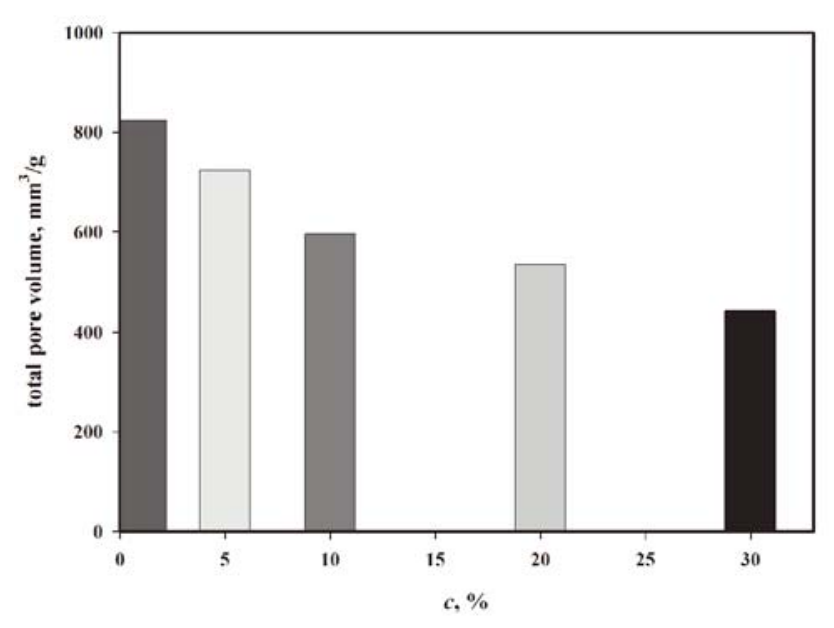

Figure 6. Effect of base concentration on the total pore volume of recovered silica

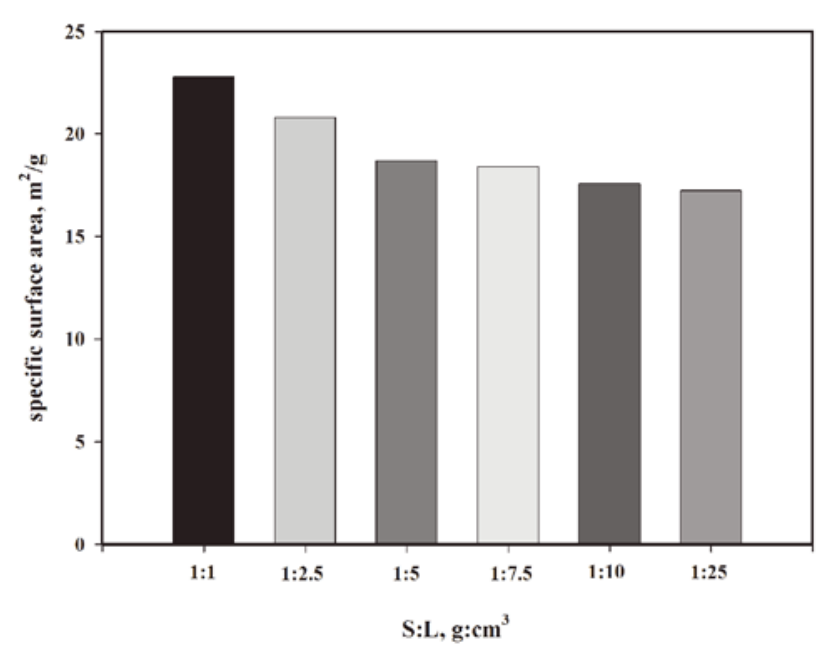

Figure 7. Effect of S:L on the specific surface area of the recovered silica

improved parameters over the silica recovered from leaching with a acidic solution. Alkaline leaching results in a silica characterised with a total pore volume about 200-300 $\mathrm{m}^{3} \cdot \mathrm{g}^{-1}$ greater than the silica obtained through analogous conditions using acid (Figure 8). The specific surface area of the silica obtained through alkaline leaching is around $2-3 \mathrm{~m}^{2} \cdot \mathrm{g}^{-1}$ greater than in the case of acidic leaching (Figure 9).

However one of the most important parameters of the silica, crucial for its ability to be used in the production of vanadium catalysts is its iron compounds content. Iron causes significant degradation of the physical and catalytic properties of the catalyst, independently from the amount and form in which it enters the catalyst ${ }^{\mathbf{9 - 1 1}}$.

In the case of alkaline leaching, due to iron's poor solubility in alkali and independently from the type of leaching or the iron content of the spent vanadium catalyst, the level of iron impurities in the reclaimed silica 


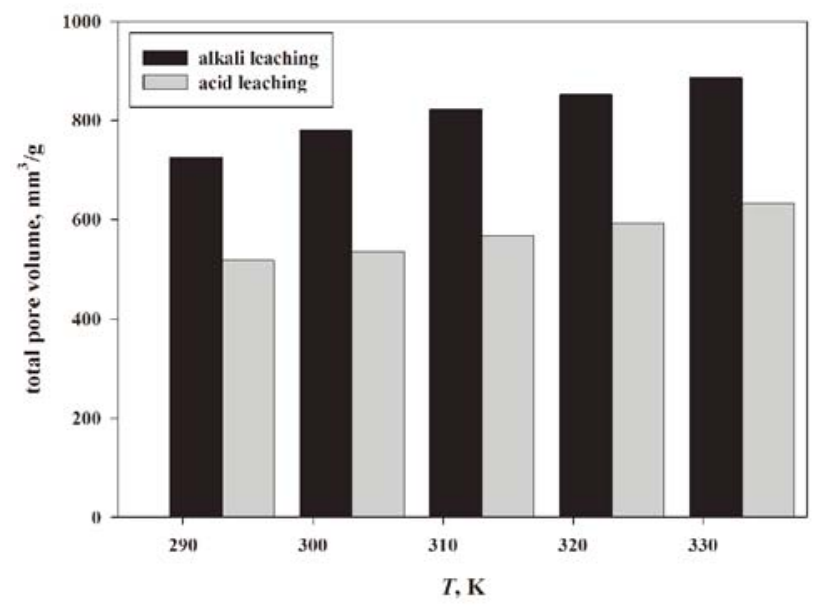

Figure 8. The total pore volume of the recovered silica as a function of temperature

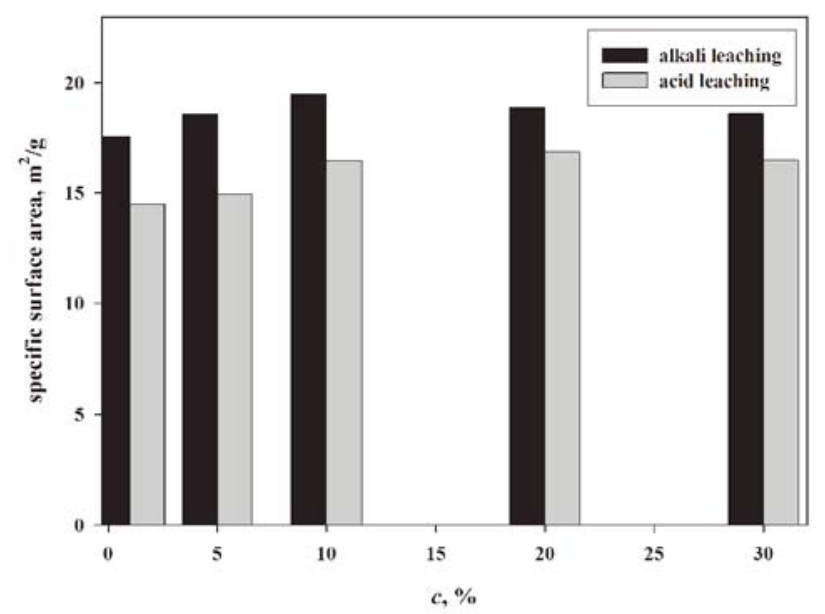

Figure 9. Effect of leaching factor concentration on the specific surface area of the recovered silica

is relatively high and usually exceeds the $0.5 \%$ impurity limit required by the technological process.

It is possible to additionally wash out iron compounds from the silica with acid to achieve the impurity limit required for the vanadium catalyst production process. However, this is unfeasible from an economic point of view. Therefore it seems useful that the silica obtained through alkaline leaching be washed out to $\mathrm{pH}$ around 6-7 and used for processing into industrial aggregate or backfill material.

\section{Ion exchange}

Figure 10 shows a graphical interpretation of the findings concerning the effects of the $\mathrm{pH}$ of the solution on the vanadium ion adsorption on Amberlite ${ }^{\circledR}$ IRA958 and Dowex ${ }^{\circledR} 1 \mathrm{X} 2$ anionites. The anionites used in the investigation are characterized by their high affinity to vanadium ions. The data presented in the figure show the significant effect of the solution's $\mathrm{pH}$ on vanadium ion adsorption. At $\mathrm{pH} 14$ vanadium ion $\mathrm{VO}_{3}{ }^{-}$adsorption is around $9 \%$ for both investigated anionites. Changing the solution's $\mathrm{pH}$ to 12 causes a significant increase in vanadium ion adsorption to $67 \%$ and $52 \%$, respectively for Amberlite ${ }^{\circledR}$ IRA958 and Dowex ${ }^{\circledR}$ 1X2. The highest adsorption for both investigated anionites was around 97\%, observed at $\mathrm{pH} 8$.

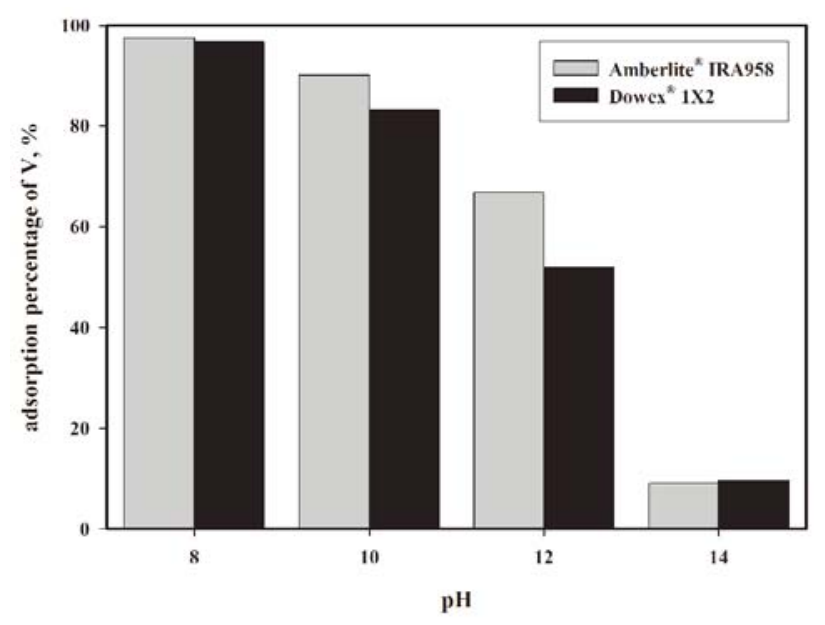

Figure 10. Effect of $\mathrm{pH}$ on the efficiency of adsorption of vanadium ion on the Amberlite ${ }^{\circledR}$ IRA958 and Dowex ${ }^{\circledR} 1 \mathrm{X} 2$ ion exchange resin $(T=303.15 \mathrm{~K}, \tau=1 \mathrm{~h})$

Figure 11 shows the results of the investigation determining the effect of the duration of the contact between the solution and the anionite on vanadium ion adsorption. Increasing the duration of contact between the solution and the anionite insignificantly increased the degree of adsorption. After 15 minutes of shaking of the investigated samples the degree of vanadium anions adsorped was $93 \%$, and above $97 \%$ after 3 hours.

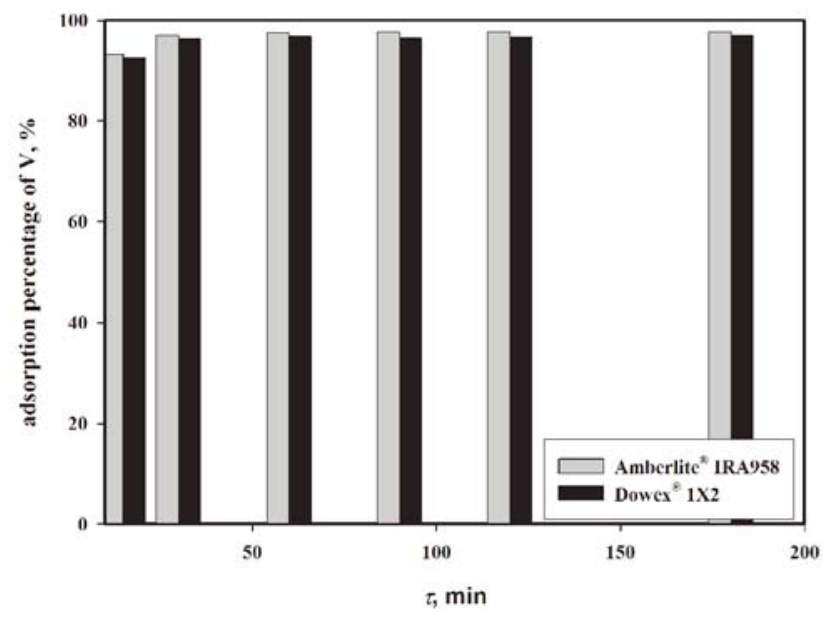

Figure 11. Effect of contact time on the efficiency of adsorption of vanadium ion on the Amberlite ${ }^{\circledR}$ IRA958 and Dowex ${ }^{\circledR}$ $1 \mathrm{X} 2$ ion exchange resin $(T=303.15 \mathrm{~K}, \mathrm{pH}=8)$

Figure 12 shows the relationship between the degree of vanadium anion adsorption and the temperature of the process. Increasing the temperature of the process from 293.15 to $323.15 \mathrm{~K}$ results in small changes in the efficiency of the adsorption process for both investigated anionites.

The results of the investigations meant to determine the effects of the solutions volume on the degree of vanadium ion adsorption on Amberlite ${ }^{\circledR}$ IRA958 and Dowex $^{\circledR} 1 \mathrm{X} 2$ ion exchangers are presented in Figure 13. Along with the increase in the solutions volume the degree of vanadium anion adsorption decreases. Using a solution with a volume of $5 \mathrm{~cm}^{3} 98$ and $97 \%$ degrees of vanadium anion adsorption were achieved respectively, while using $25 \mathrm{~cm}^{3} 85$ and $90 \%$ degrees of adsorption were observed respectively. 


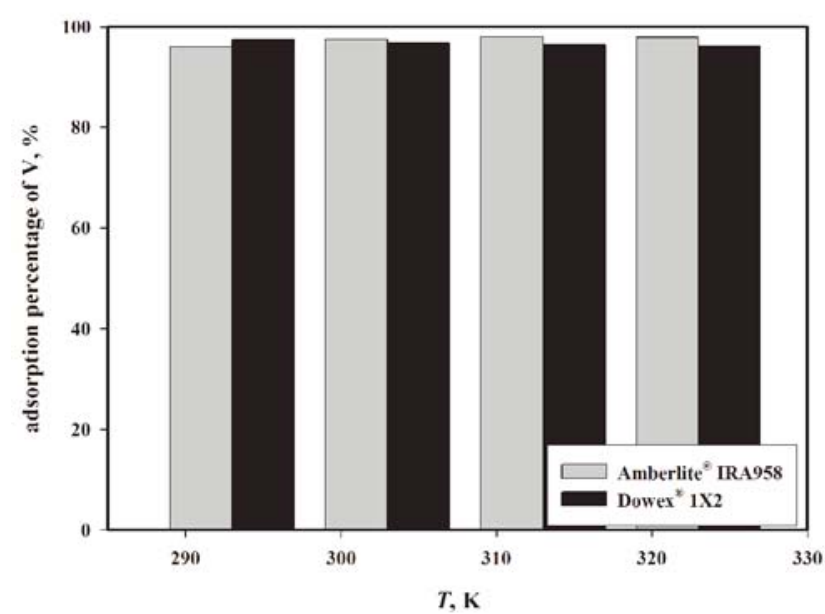

Figure 12. Effect of temperature on the efficiency of adsorption of vanadium ion on the Amberlite ${ }^{\circledR}$ IRA958 and Dowex ${ }^{\circledR}$ $1 \mathrm{X} 2$ ion exchange resin $(\tau=1 \mathrm{~h}, \mathrm{pH}=8)$

Technological process of managing waste from a spent vanadium catalyst

The results of investigating leaching a spent vanadium catalyst with a solution of potassium hydroxide showed that the process is highly effective and very beneficial when using the leachate solution directly in the production of new catalyst mass. Components of the leachate solution are mainly potassium and vanadium compounds that do compounds constitute the active phase of the

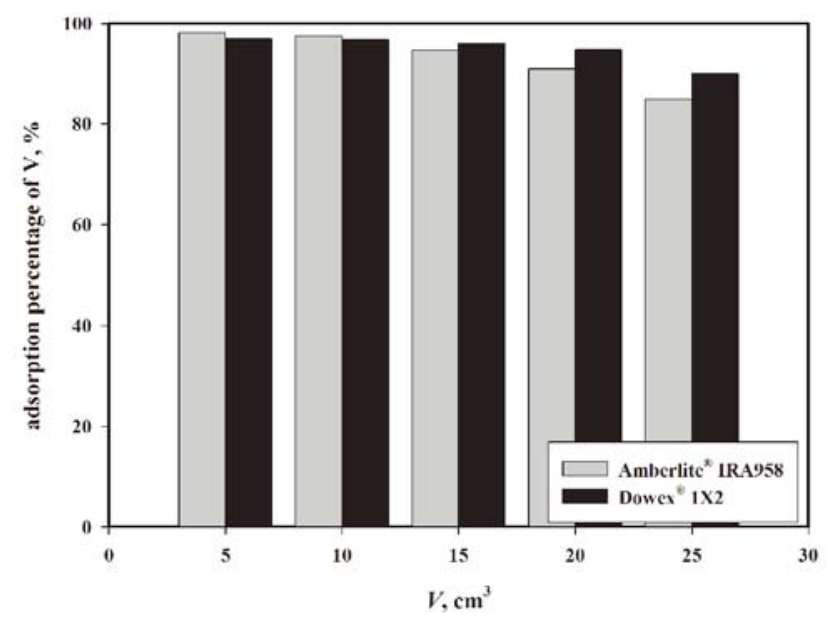

Figure 13. Effect of solution volume on the efficiency of adsorption of vanadium ion on the Amberlite ${ }^{\circledR}$ IRA958 and Dowex $^{\circledR} 1 \mathrm{X} 2$ ion exchange resin $(T=303.15 \mathrm{~K}, \tau=$ $1 \mathrm{~h}, \mathrm{pH}=8$ )

catalysts. The total degree of contamination of the leachate with the remaining components of a metallurgic catalyst does not exceed $30 \mathrm{ppm}$. This solution, after composition adjustment and possible evaporation of some of the water, could be used directly in producing catalysts with the wet method.

Vanadium compounds can also be removed from the solution through ion exchange. The concentrated vanadium solution obtained through elution could also

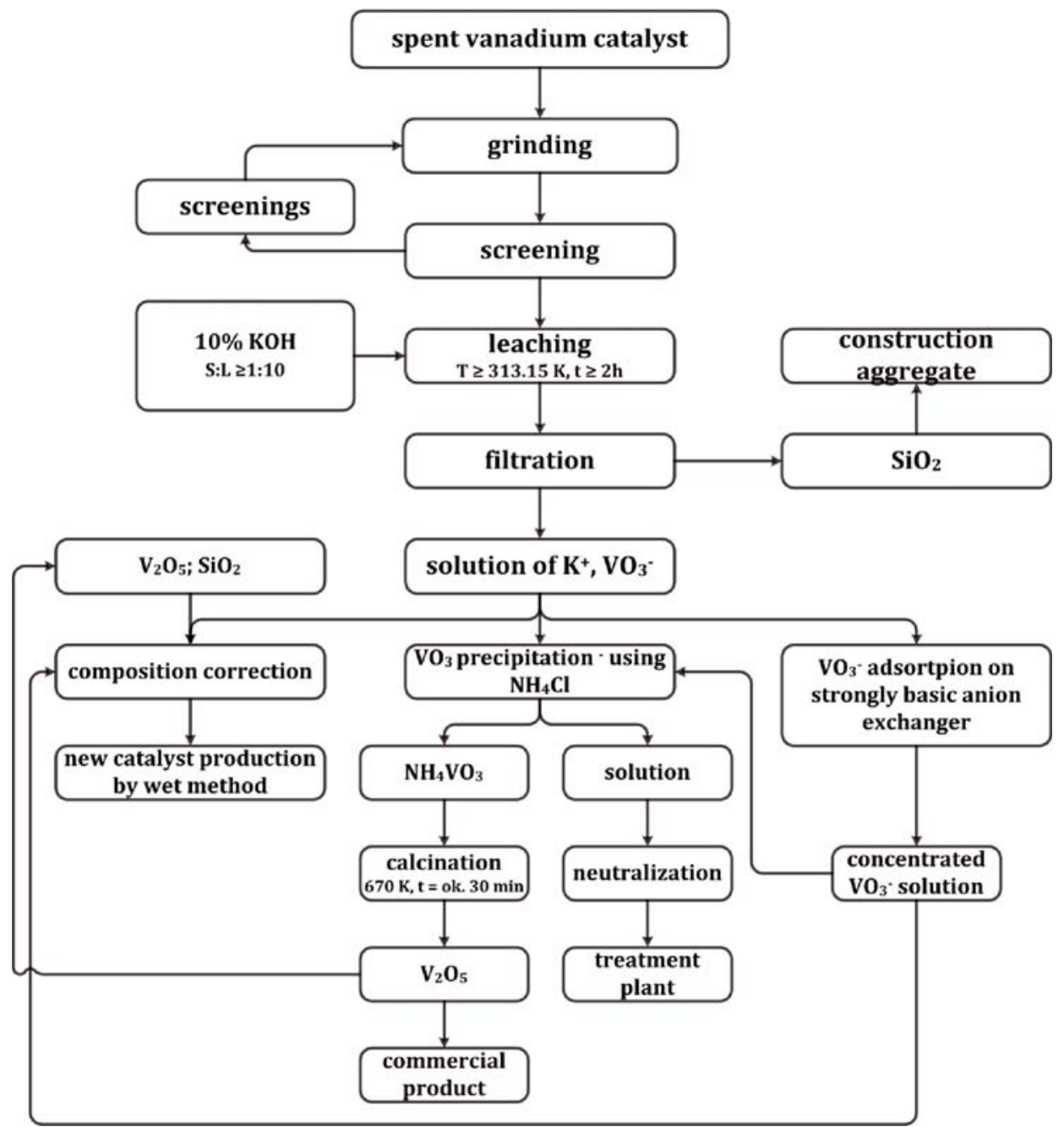

Figure 14. A conceptual process flow sheet for the recovery of vanadium from spent catalyst by potassium hydroxide solution leaching, ion exchange and precipitation 
be used for adjusting the composition of the solution meant for producing fresh catalyst mass. Moreover, through precipitation, it can be used to extract vanadium compounds as a commercial product. Ammonium chloride can be used to extract ammonium vanadate(V). Research has shown that when using ammonium chloride as a precipitation agent it is necessary to use it in excess ${ }^{12-14}$. The excess ammonium chloride not only pushes the reaction equilibrium towards the products, but also salts out ammonium vanadate $(\mathrm{V})$ through the common-ion effect. The pure ammonium vanadate $(\mathrm{V})$ obtained this way can be then calcined to obtained high quality vanadium $(\mathrm{V})$ oxide.

The conceptual flow sheet for the comprehensive management of spent vanadium catalyst using potassium hydroxide solutions is shown in Figure 14.

\section{SUMMARY}

Potassium hydroxide, can be used for the recovery of vanadium from spent vanadium catalyst. The obtained yields for vanadium compounds are satisfactory from the technological point of view. Maximum degree of vanadium recovery from the used vanadium catalyst $(87 \%)$ was achieved for the extraction conditions: $10 \% \mathrm{KOH}$, $\mathrm{T}=313.15 \mathrm{~K}, \mathrm{t}=4 \mathrm{~h}, \mathrm{~S}: \mathrm{L}=1: 20, \varphi:$ less than $750 \mathrm{~mm}$. Vanadium can be separated, purified and recovered from the solution by ion exchange method. The post-leaching solution can be used for the production of fresh catalyst.

\section{LITERATURE CITED}

1. Drużyński, S., Mazurek, K. \& Białowicz, K. (2014). The use of ion exchange in the recovery of vanadium from the mass of a spent catalyst used in the oxidation of $\mathrm{SO}_{2}$ to $\mathrm{SO}_{3}$. Pol. J. Chem. Technol. 16(2), 69-73. DOI: 10.2478/pjct-2014-0032.

2. Mazurek, K. (2014). Removal of vanadium, potassium and iron from spent vanadium catalyst by leaching with citric acid at atmospheric pressure. Pol. J. Chem. Technol. 16(1), 59-62. DOI: $10.2478 /$ pjct-2014-0010.

3. Mazurek, K. (2012). Extraction of vanadium and potassium compounds from the spent vanadium catalyst from the metallurgical plant. Pol. J. Chem. Technol. 14(2), 49-53. DOI: 10.2478/v10026-012-0070-9.

4. Khorfan, S., Wahoud, A. \& Reda Y. (2001). Recovery of vanadium pentaoxide from spent catalyst used in the manufacture of sulphuric acid. Periodica Polythechnica Ser. Chem. Eng. 45(2), 131-137.

5. Mohanty, J., Rath, P.C., Bhattacharya, I.N. \& Paramguru, R.K. (2011). The recovery of vanadium from spent catalyst: a case study. Mineral Processing and Extractive Metallurgy 120, 56-60. DOI: 10.1179/037195510X12772935654909.

6. Magnani, J.L., Kachan, G.C. \& Ferreira, N.L. (2000). Vanadium recovery by leaching in spent catalyst for sulfuric acid production. Rev. Ciencia Technol. 8, 85-90.

7. Lozano, L.J. \& Juan, D. (2001). Leaching of vanadium from spent sulphuric acid catalysts. Miner. Eng. 5, 543-546. DOI: 10.1016/S0892-6875(01)00042-5.

8. Brouwer, P. (2006). Theory of XRF. Almelo, Netherlands: Panalytical.

9. Grobela, M. \& Grzesiak, P. (2007). The influence of iron compounds in the sulfuric acid catalyst on the $\mathrm{SO}_{2}$ oxidation process. Pol. J. Chem. Technol. 1(9), 2-6. DOI: 10.2478/v10026007-0002-2.

10. Grzesiak, P., Grobela, M. \& Motała, M. (2007). The influence of the catalyst worktime on $\mathrm{SO}_{2}$ emission quantity from the sulfuric acid system and the catalyst waste material.
Pol. J. Chem. Technol. 3(9), 134-137. DOI: 10.2478/v10026007-0073-0. 1_3_2018 (612) Mazurek

11. Ksibi, M., Elaloui, E., Houas, A. \& Moussa, N. Diagnosis of deactivation sources for vanadium catalyst used in $\mathrm{SO}_{2}$ oxidation reaction and optimization of vanadium extraction from deactivated catalysts. Appl. Surf. Sci. 220, 105-112. DOI: 10.1016/S0169-4332(03)00748-7.

12. Mazurek, K. \& Grzesiak, P. (2017) Separation of vanadium ions from the post - leaching solution of spent vanadium catalyst. Przem. Chem. 6 (96), 1390-1393. DOI: 10.15199/62.2017.6.36.

13. Zeng, L. \& Cheng, C.Y. (2009). A literature review of the recovery of molybdenum and vanadium from spent hydrodesulphurization catalysts. Part I: metallurgical processes. Hydrometallurgy 98, 1-9. DOI: 10.1016/j.hydromet.2009.03.010.

14. Zeng, L. \& Cheng, C.Y. (2009). A literature review of the recovery of molybdenum and vanadium from spent hydrodesulphurization catalysts. Part II: separation and purification. Hydrometallurgy 98, 10-20. DOI:10.1016/j.hydromet.2009.03.012. 